\title{
Lung function studies before and after a work shift
}

\author{
R G LOVE
}

From the Institute of Occupational Medicine, Edinburgh EH8 9SU, UK

\begin{abstract}
The lung function of 23 underground coal workers and eight surface workers at a Scottish colliery was measured immediately before and after a work shift. Changes in lung function were assessed in relation to the measured respirable dust exposure and the time of day in which the shift was worked. Large, and statistically significant, decrements of lung function during the shift were found in night-shift workers compared with workers on other shifts. Measurements derived from the forced expiratory manoeuvre, particularly $\mathrm{FEV}_{1}, \dot{\mathrm{V}}_{\max }$, and $\dot{\mathrm{V}}_{\mathrm{max}}$, after three vital capacity breaths of an $80 \% \mathrm{He} / 20 \% \mathrm{O}_{2}$ mixture, showed large reductions in night-shift men, smaller reductions in afternoon-shift men, and small increases or decreases in morning-shift underground and surface workers. Within-shift changes for other tests, such as closing volume, $\mathrm{N}_{2}$ index, and volume of isoflow, did not differ significantly between shifts. No significant relationship was found between dust exposure and functional changes during a shift for any test. Lung function changes in a control group of 25 female workers not exposed to dust (hospital nurses) did not show the same large variations between day and night shifts. Examination of a further control group of 16 office workers did not show any difference in diurnal changes between smokers and non-smokers. It is concluded that these coal miners, even on permanent shift patterns, had widely different changes in their lung function cycle depending on which shift they were working. These changes did not appear to be related to dust exposure or cigarette smoking and were not consistent with other biological adaptations known to result from regular night-shift working.
\end{abstract}

The results of an investigation of coal miners ${ }^{1}$ in the United States indicated that decrements of lung function over a shift, particularly maximum expiratory flow at low lung volumes, were correlated with the estimated average dustiness of a coal miner's job underground. It was also observed that these findings applied to miners whatever time of day (shift) they worked. (These men had been employed on a particular shift for at least two consecutive weeks before the study.)

Since the actual dust exposures of the miners in that study ${ }^{1}$ were not measured, the present study was carried out to investigate further the relationship between dust exposure measured during a work shift and changes in lung function.

Coal miners exposed to a range of airborne dust levels and working different shifts were examined before and after a normal shift, in order that the acute effects of breathing coal-mine dust on lung function could be examined. Subjects who had not been

Received 18 March 1982

Accepted 18 May 1982 exposed to dust were also examined, so that the additional effects of time of day and tobacco smoking on changes in lung function could also be investigated.

\section{Material and methods}

Thirty-two underground coal workers from a colliery in Scotland who regularly carried airborne dust sampling instruments to their place of work for research purposes were selected to act as subjects. Of these men, 23 (aged 23-59) could take part in the study. Ten men worked on the morning shift (7 am$215 \mathrm{pm}$ ), seven the afternoon shift ( $215 \mathrm{pm}-930$ $\mathrm{pm}$ ) and six the night shift (11 pm-6 $15 \mathrm{am})$. In addition eight day-shift surface workers, who had never worked underground and were not exposed to appreciable amounts of airborne dust during their work, had their lung function measured before and after a normal shift. Table 1 gives the characteristics of all these men.

Six men worked the morning shift constantly and another four on this shift alternated weekly with the afternoon shift. All but one current afternoon-shift 
worker alternated weekly with the morning shift and all night-shift men worked this shift exclusively.

Two men at a time attended at a mobile laboratory at the colliery immediately before their shift, and again as soon after their shift as possible. On both occasions smokers were asked not to smoke for at least an hour before the tests.

Subsequently, 25 nursing and technical staff (all women) volunteered to be examined at a local hospital to investigate the possible effect of shift work on workers not occupationally exposed to a dusty environment. This group consisted of seven nurses and five laboratory technicians on day shift and 13 nurses on night shift. The subjects attended at a laboratory at the hospital immediately before their shift at 815 am or $815 \mathrm{pm}$ and again immediately after work at $430-500 \mathrm{pm}$ or 730 am respectively.

Finally, 16 male office and laboratory workers from this institute were examined three times, at the beginning $(9 \mathrm{am})$, middle $(12 \mathrm{pm})$ and end $(5 \mathrm{pm})$ of a normal working day. Eight were smokers (aged 2349) and eight were non-smokers (aged 24-40).

The following measurements were made at each visit for the coal miners. Lung volumes were measured by multiple breath helium dilution from which vital capacity (VC), functional residual capacity (FRC), residual volume (RV), and total lung capacity (TLC) were derived. Forced expiratory manoeuvres using air and after three $\mathrm{VC}$ breaths of an $80 \%$ helium $/ 20 \%$ oxygen mixture were performed, and forced vital capacity (FVC), forced expiratory volume in one second $\left(\mathrm{FEV}_{\mathrm{f}}\right)$, maximum expiratory flow at $50 \%$ and $25 \%$ of FVC $\left(\operatorname{Vmax}_{50}\right.$ and $\dot{\mathrm{V}} \max _{25}$ ) breathing air and $\mathrm{He} / \mathrm{O}_{2}$, and volume of isoflow ( $\mathrm{V}$ iso $\dot{\mathrm{V}})$ were measured from the best of at least three technically satisfactory flow/volume curves on air and two such curves on $\mathrm{He} / \mathrm{O}_{2}$. The curve with the largest FVC was selected for analysis and $\mathrm{V}$ iso $\dot{\mathrm{V}}$ was measured by aligning the best air and $\mathrm{He} / \mathrm{O}_{2}$ curves at $\mathrm{RV} .{ }^{2}$ Forced expiratory time (FET) was also recorded by a timer activated by the expiration of the first $100 \mathrm{ml}$ of air and stopped once the flow had fallen below $50 \mathrm{ml} / \mathrm{s}$.

The single breath nitrogen test was also carried out at each visit, at least three times on each subject. The alveolar plateau in the form of the $\mathrm{N}_{3}$ concentration difference between 750 and $1250 \mathrm{ml}\left(\triangle \mathrm{N}_{2} \%_{750-1250}\right.$ or the $\mathrm{N}_{2}$ index) was measured and the closing volume and closing capacity $(C R+R V)$ were also derived from this manoeuvre. Only measurements derived from the forced expiratory manoeuvres were taken for the nurses and office workers.

A brief job description was obtained for each miner, and his age, height, weight, smoking habits, and any appreciable cardiorespiratory abnormalities were recorded at his first visit. Table 1 gives the mean ages and anthropometric data for each group of miners, nurses, and office workers.

MRE Type 113A gravimetric respirable dust samplers were carried and positioned near to their place of work by the coal miners who had worked underground. The respirable dust concentrations measured gave a time weighted shift mean concentration for each man.

In practice the miners attended the laboratory at the time they normally went to their place of work and as a result were ready for work about half an hour later than usual and were a similar amount early when leaving work. Underground workers often did not go underground until about an hour after their normal time and sometimes came up an hour early. In addition some men were not deployed to their normal place of work once they had arrived underground and consequently were often exposed to less dusty conditions than usual.

STATISTICAL METHODS

The change in each lung function variable from its

Table 1 Personal details of study population. (Standard deviations in parentheses)

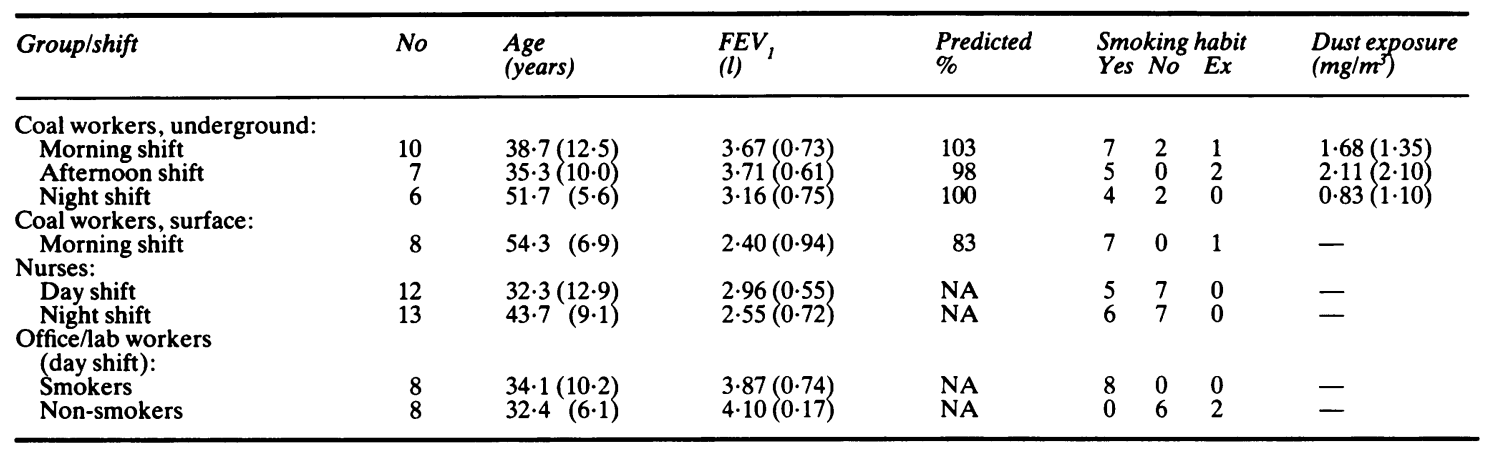

NA $=$ Not available. 
value before $\left(x_{1}\right)$ to its value after $\left(x_{2}\right)$ the shift was expressed as follows:

$\triangle x(\%$ difference $)=\frac{x_{2}-x_{1}}{\frac{1}{2}\left(x_{1}+x_{2}\right)} \times 100$

The largest value was selected from those technically satisfactory readings of variables derived from the forced expiratory manoeuvres, while the average of three values was used for readings derived from the single-breath nitrogen test. Paired $t$ tests were used for analysing differences between start and end of the shift.

\section{Results}

\section{COALWORKERS}

Table 1 gives the mean dust concentrations for underground workers on the three shifts. Only seven men were exposed to respirable dust concentrations greater than $2 \mathrm{mg} / \mathrm{m}^{3}$ and 13 readings were less than 1 $\mathrm{mg} / \mathrm{m}^{3}$.

When the subjects were examined according to the shift they worked, the considerable differences in the

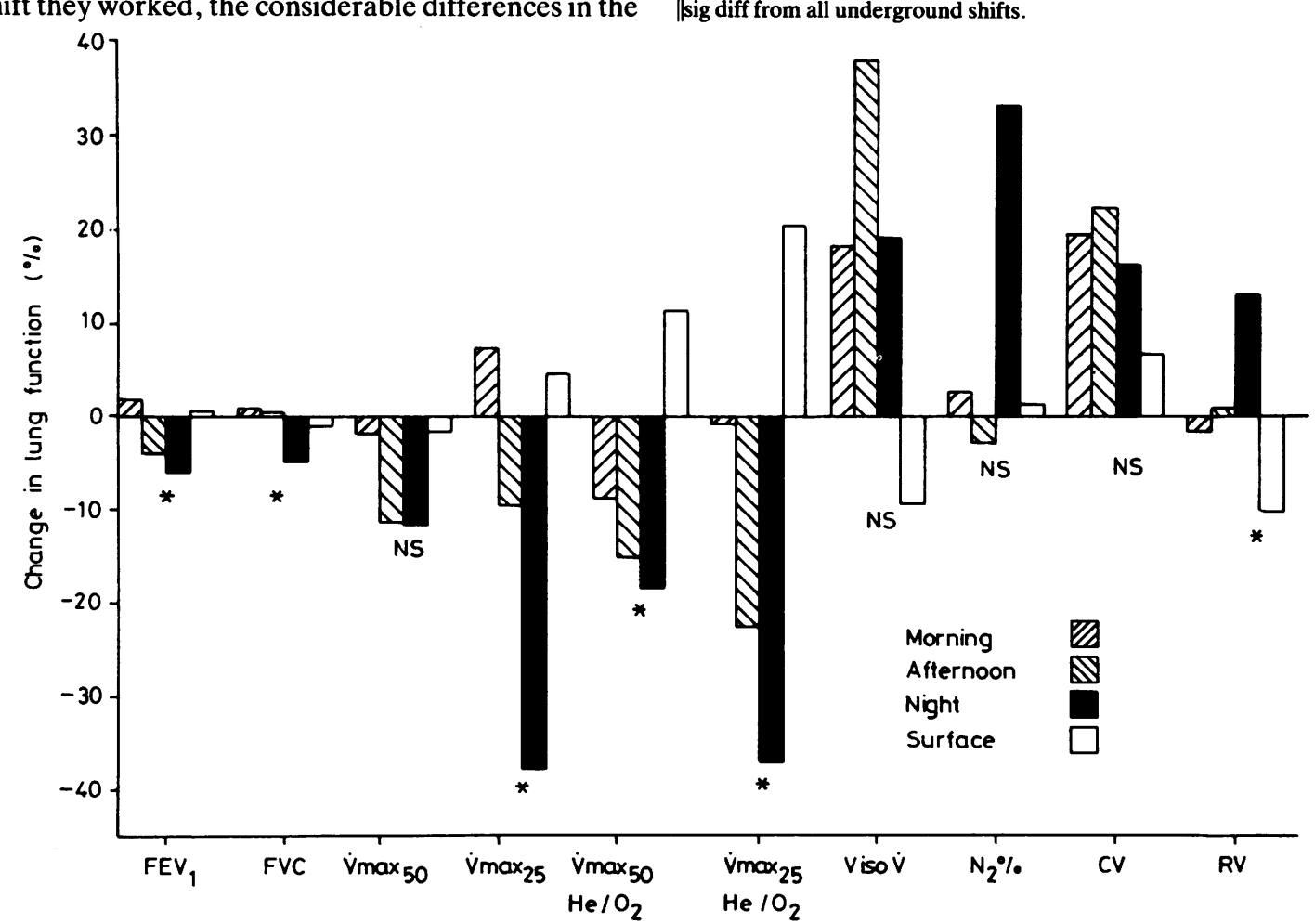

degree and direction of change of some of the lung function variables were unrelated to the actual dust exposure. Table 2 and fig 1 show that indices derived Table 2 Changes in lung function during a working shift for underground workers on day, back, and night shifts and for surface workers on day-shift

\begin{tabular}{|c|c|c|c|c|}
\hline $\begin{array}{l}\text { Lung function } \\
\text { test }\end{array}$ & $\begin{array}{l}\text { Underg } \\
D S\end{array}$ & BS & NS & $\begin{array}{l}\text { Surface workers } \\
D S\end{array}$ \\
\hline 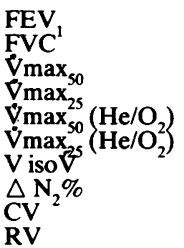 & $\begin{array}{r}+1.8 \\
+0.9 \\
-1.7 \\
+7.6 \\
-8.4 \\
-0.7 \\
+18.4 \\
+2.9 \\
+19.5 \\
-1.4\end{array}$ & $\begin{array}{c}-3 \cdot 7 \dagger \\
+0.3 \\
-11 \cdot 3 \\
-9.4 \\
-14 \cdot 7 \\
-22 \cdot 4 \\
+38 \cdot 1 \\
-2 \cdot 7 \\
+22 \cdot 5 \\
+1 \cdot 1\end{array}$ & $\begin{array}{l}-5 \cdot 9 \dagger \ddagger \\
-4 \cdot 7 \dagger \\
-11 \cdot 6 \\
-37 \cdot 7 \S \\
-18 \cdot 2 \dagger \\
-37 \cdot 1 \dagger \\
+19 \cdot 3 \\
+33 \cdot 2 \\
+16 \cdot 3 \\
+13 \cdot 2 \ddagger\end{array}$ & $\begin{array}{c}+0.5 \\
-0.9 \\
-1.5 \\
+4.7 \\
+11.6 \\
+20.6 \\
-9.3 \\
+1.5 \\
+6.8 \\
-10.1\end{array}$ \\
\hline
\end{tabular}

Figures are $\%$ differences pre- to postshift.

$=\frac{\text { Post- preshift value }}{\text { Mean of pre- and postshift values }} \times 100$

Differences between shifts were statistically significant

$(p<$ or $<0.05)$ in the following ways:

tsig diff from DS;

$\ddagger$ sig diff from surface;

$\S$ sig diff from DS, BS, and surface;

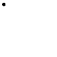


from the forced expiratory manoeuvre, notably changes of $\mathrm{FEV}$ and $\mathrm{Vmax}$ on air and $\mathrm{He} / \mathrm{O}_{2}$, showed large and highly significant differences between the three underground shift groups and between some of these groups and the surface workers.

$\mathrm{FEV}_{1}$ of night-shift workers, for example, fell $5.9 \%$, which was significantly different $(\mathrm{p}<0.02)$ from that of surface workers, whose FEV increased by $0.5 \% . \triangle \mathrm{FEV}$, of morning-shift underground workers $(+1.8 \%)$ was also very different from $\triangle F_{1}$ of other underground workers $(\mathrm{p}<0.001)$.

$\dot{\mathrm{V}} \max _{25}\left(\mathrm{He} / \mathrm{O}_{2}\right)$ increased by $20.6 \%$ for surface workers but fell by $0.7 \%, 22 \cdot 4 \%$, and $37.1 \%$ for morning, afternoon, and night-shift underground workers respectively. Most of these differences were statistically significant.

Volume of isoflow and measurements derived from the single breath nitrogen test-that is, $\mathrm{N}_{2}$ index and closing volume-showed no relationship with the shift worked but residual volume of night-shift workers increased significantly compared with the surface shift (table 2).

There appeared, however, to be little or no discernible relationship between changes in lung function and dust exposure during a shift. The highest correlation observed between the change in any lung function variable and dust exposure for all underground workers combined was with $\dot{V} \max _{25}$ ( $r$ $=0 \cdot 29, \mathrm{t}=1 \cdot 30$ ), although even this was well below the conventional level of statistical significance.

NURSES

The changes in lung function during a shift were generally small on average (table 3 and fig 2). FEV fell slightly in daytime workers and $\mathrm{Vmax}_{25}$ and $\mathrm{FEV}$, $\left(\mathrm{He} / \mathrm{O}_{2}\right)$ both fell during their shift for night workers. Although all but one of the tests had changed more adversely for night than for day staff, no test was

Table 3 Changes in lung function during a working shift for female hospital nursing and technical staff on day and night shifts

\begin{tabular}{|c|c|c|c|c|}
\hline \multirow{2}{*}{$\begin{array}{l}\text { Lung function } \\
\text { test }\end{array}$} & \multicolumn{2}{|c|}{ Day shift } & \multicolumn{2}{|c|}{ Night shift } \\
\hline & Air & $\mathrm{HelO}$ & Air & $\mathrm{HelO}_{2}$ \\
\hline $\begin{array}{l}\text { FEV } \\
\text { FVC } \\
\text { V́max }_{50} \\
\text { Vmax }_{25} \\
\text { FET }\end{array}$ & $\begin{array}{l}-1.2 * \\
-2.3 \\
+2.1 \\
-8.8 \\
+5.8\end{array}$ & $\begin{array}{r}-1.0 \\
-0.7 \\
+1.4 \\
-4.8 \\
+12.1\end{array}$ & $\begin{array}{c}-1.7 \\
-2.9 \\
-3.0 \\
-13.2 \\
+11.7\end{array}$ & $\begin{array}{c}-4 \cdot 6^{*} \\
-2 \cdot 8 \\
-7 \cdot 2 \\
-10 \cdot 1 \\
+10 \cdot 8\end{array}$ \\
\hline
\end{tabular}

${ }^{*}$ Change is significantly different from zero $\mathrm{p}<0.05$.

No difference between day and night shifts was statistically significant for any test.

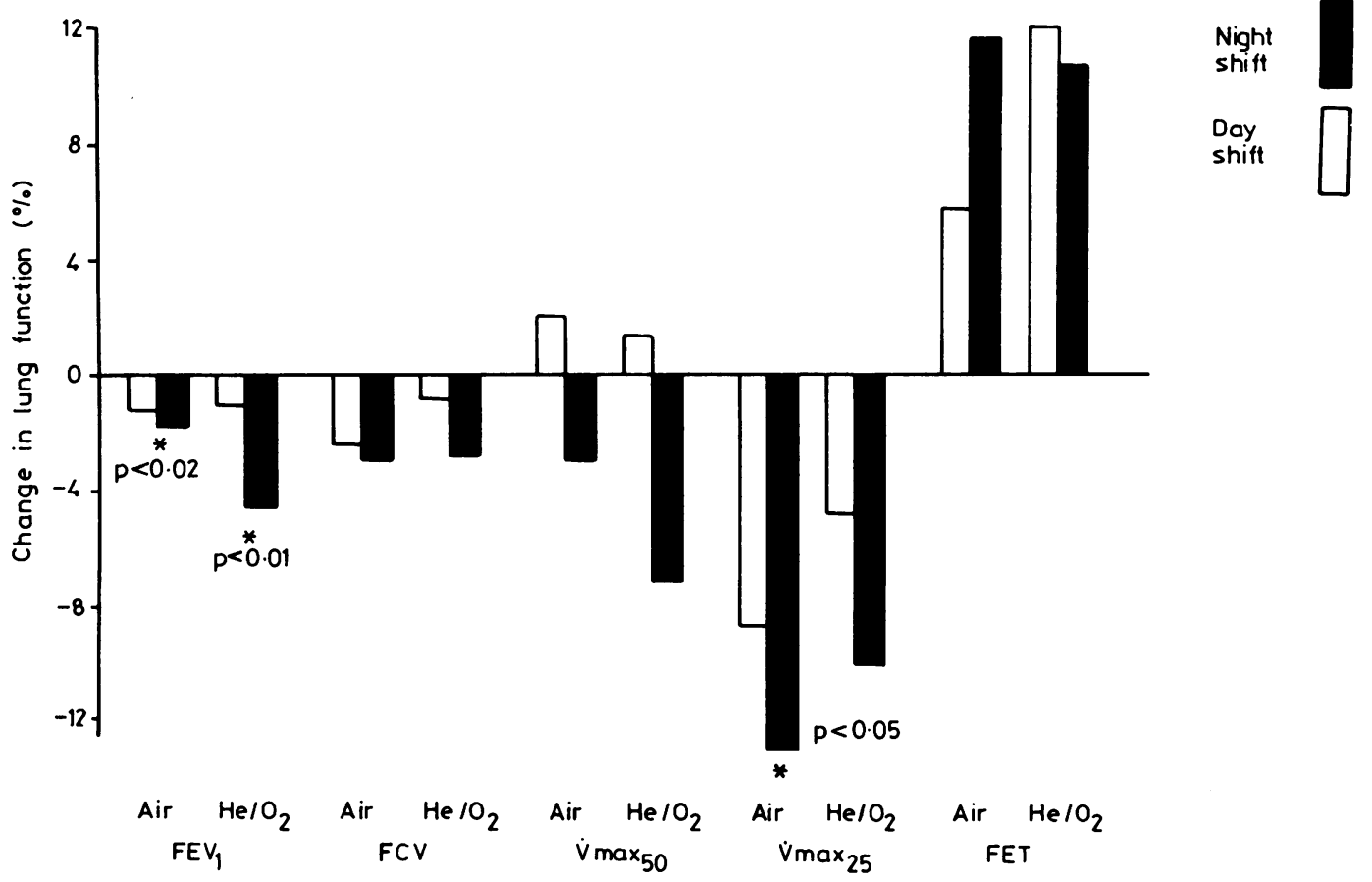

Fig 2 Percentage changes in lung function for nurses on day and night shifts - forced expiratory manoeuvres breathing air and $80 \% \mathrm{He} / 20 \% \mathrm{O}$.

* Change is significantly different from zero. 
significantly different between these two groups. In general the changes for each variable were in the same direction for both groups - that is, $\mathrm{FEV}_{1}, \mathrm{FVC}$, and $\dot{V} \max _{25}$ declined, while $\dot{\mathrm{V}} \mathrm{max}_{50}$ increased slightly, except on air for day workers.

\section{LABORATORY/OFFICE WORKERS}

Forced expirations were carried out as before at each visit, and on average lung function improved for all tests between 9 am and 12 noon (fig 3). This improvement was always greater than the difference between the values measured at 9 am and $5 \mathrm{pm}$. At 5 pm $\operatorname{Vmax}_{50}\left(\mathrm{He} / \mathrm{O}_{2}\right)$ had shown a small decrease compared with the 9 am value in both smokers and non-smokers, but $\dot{V} \max _{25}\left(\mathrm{He} / \mathrm{O}_{2}\right)$ decreased only in smokers. All other tests were still higher at $5 \mathrm{pm}$.

The size of these changes did not differ significantly between smokers and non-smokers in this study, although the former had slightly greater increases in $\mathrm{FEV}_{1}, \mathrm{FVC}, \dot{\mathrm{V}} \mathrm{max}_{50}$, and $\mathrm{Vmax}_{25}$ between 9 am and 12 noon. The overall changes between 9 am and 5 pm were no greater than $3 \%$ but some quite large individual differences occurredfor instance, a $10 \%$ increase in $\mathrm{FEV}_{1}$ in one subject.

\section{Discussion}

The results of this study indicate that considerable differences between workers may exist in the changes that occur in lung function during a working shift, depending on the time of day and possibly the type of work undertaken. Mine workers on night shift have been shown to have substantially greater reductions in lung function than workers on earlier shifts, changes that are not accounted for by higher dust exposure. Workers unexposed to airborne dust, such as hospital nurses, do not appear to exhibit the same differences between night- and day-time shifts.

These large inter-shift differences found in coal miners, which were much greater for maximum expiratory air flow in the latter half of a forced expiratory manoeuvre, appear to be real and probably represent true circadian variations. Previous studies of industrial workers on day shifts suggest that lung function (FEV or FVC) exhibits a 3-4\% rise during the morning hours after waking. ${ }^{4}$ Most of this change has been shown to occur in the first two hours or so, ${ }^{5}$ which was confirmed by our results on office workers.

Our finding of a difference not only in degree but also of direction between miners on different shifts conflicts with the claim that workers on different shifts can be grouped together if they have worked a particular shift constantly for at least two weeks. ${ }^{1}$ In the present study there is a residual shift effect to the extent that miners on afternoon and night shifts experience an increasingly greater loss of lung function during their working hours. Most of the dayshift men and all the night-shift men had been on these shifts for at least several weeks. They would therefore be expected to have adapted in such a way that the circadian rhythms of the night workers would have been similar to those of day workers. ${ }^{6}$

The mineworkers on afternoon shift, however,

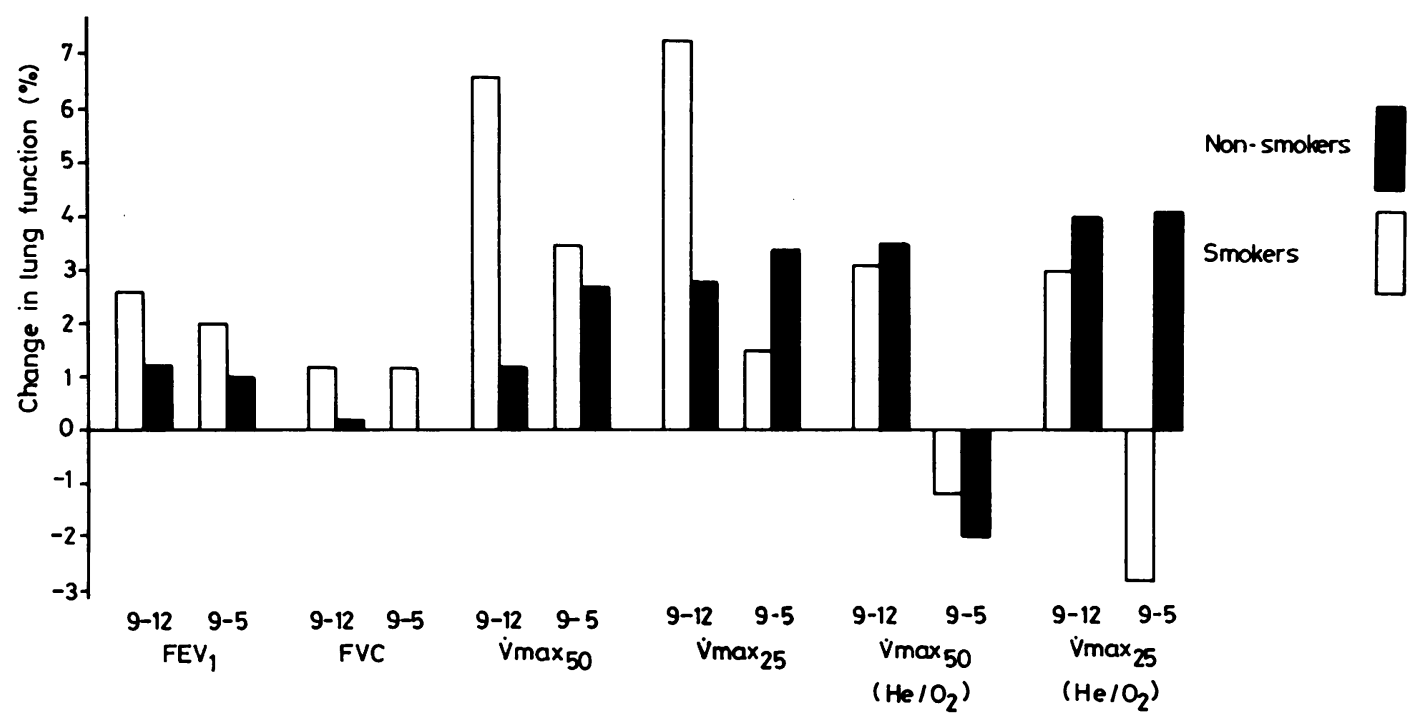

Fig 3 Percentage changes in lung function (forced expiratory manoeuvres breathing air and $80 \% \mathrm{He}_{2} 20 \% \mathrm{O}_{2}$ ) of laboratory and office workers on day shift: smokers and non-smokers. 
while mostly on the first day of this shift (which they alternated weekly with the morning shift), exhibited changes intermediate to those on the other two shifts. In other words, their lung function showed a moderate decrease during the afternoon and evening hours, which is expected for workers on a normal night/day sleep/work pattern. ${ }^{3}$ The night workers seemed to be behaving as if they had not adapted at all to their shift pattern. They exhibited the characteristics of men examined at the times of day of men on a normal diurnal cycle-that is, an improvement during the morning, a slight fall in the afternoon, and a larger fall at night.

The reasons for this unexpected finding are not obvious. Although the night workers are considerably older than the morning and afternoon workers, by 13 and 16 years respectively, the surface workers (on day shift) were even older than the night workers, yet their functional changes were similar to those of the underground workers on the morning shift. It is not known when during the day the night-shift workers slept, but almost certainly it would have been immediately after work, according to recognised habits of other permanent night workers. ${ }^{\text {? }}$ In that case these men would be on the descending part of their curve of biological rhythm, which in regular day workers begins during the evening before retiring. The large and consistent falls of $\mathrm{FEV}_{1}$, which are much greater in magnitude than the increases in morning workers, cannot, however, be related to the lack of adaptation to a rotating shift pattern, since all these men were permanent night-workers. Although four men were examined on Monday night (their first night at work after the weekend), their lung function changes were similar to the men examined later in the week. Therefore, one cannot assume that workers, who may have been on a shift for several weeks, are biologically fully adapted to the new cycle.

The lack of any relationship between lung function changes and respirable dust exposure confirms the findings of previous workers ( $\mathrm{N}$ L Lapp et al, personal communication, 1978). The average exposure of the underground workers in the present study was apparently similar to that of the miners studies by Lapp and his colleagues-that is, about $1.6 \mathrm{mg} / \mathrm{m}^{3}$ averaged over the shift. There was, however, a slight but insignificant trend for our miners with dust exposure $>3 \mathrm{mg} / \mathrm{m}^{3}$ to have a greater reduction of $\dot{V}_{\max }(-13 \%)$ when compared with miners exposed to $<3 \mathrm{mg} / \mathrm{m}^{3}(-6.5 \%)$ and surface workers not exposed to dust $(+9 \%)$, who all worked the day shift.

Surprisingly, a clearer distinction between day and night staff was not shown for the control group of hospital workers. Both groups tended to exhibit a decline in function during their shift which, although greater in night staff, was not significantly different from the changes found in day workers. Nevertheless, some of these changes during the shift were significantly different from zero (table 3 ). The night staff might have been expected to have shown a decline because they only worked for one to three nights each week and may not have been fully adapted. On the other hand, this group worked a longer shift $(830 \mathrm{pm}$ to $730 \mathrm{am})$ than the day staff (8 $30 \mathrm{am}$ to $430 \mathrm{pm}$ ) and the times of measurement before and after the shift could have been on different parts of their curve of circadian rhythm.

This lack of difference did not seem to be due to differences in smoking habits, since there were similar numbers of smokers and non-smokers in each group. No differences in lung function changes were found between non-smokers and smokers in office and laboratory workers examined before and after a day shift (table 4), confirming the findings of a recent study of a group of office workers. ${ }^{8}$

It is therefore not clear why night-shift miners should have exhibited such large decrements of lung function during their shift, particularly for $\dot{V} \max _{25}$ when breathing air or $\mathrm{He} / \mathrm{O}_{2}$. These results suggest, however, that care should be taken in interpreting data from longitudinal surveys of lung function in industrial or other working populations. The large shift or diurnal effects, in addition to the larger intraindividual variation of $\overline{\mathrm{V}} \max _{25}{ }^{9}$ may make interpretation of changes related to airborne pollutants more difficult.

Thanks are due to T D Wilson and P A Hutchison for carrying out the lung function tests, W Fairman and $\mathrm{R}$ Watson for organising the collection of dust sampling data, the management of Lady Victoria Colliery, and senior nursing officer Mackenzie of City Hospital, Edinburgh, for their co-operation, and, finally, to all the subjects who participated in this study.

Table 4 Changes in lung function of office/laboratory workers during a normal working day

(a) \% differences between 9 am and 12 noon,

(b) \% differences between 9 am and 5 pm

\begin{tabular}{|c|c|c|c|c|c|c|}
\hline & \multicolumn{2}{|c|}{$\begin{array}{l}\text { Smokers } \\
n=8 \\
\triangle 9-12 \Delta 9-5\end{array}$} & \multicolumn{2}{|c|}{$\begin{array}{l}\text { Non-smokers } \\
n=8 \\
\triangle 9-12 \Delta 9-5\end{array}$} & \multicolumn{2}{|c|}{$\begin{array}{l}\text { Total } \\
n=16 \\
\triangle 9-12 \Delta 9-5\end{array}$} \\
\hline $\begin{array}{l}F E V_{1} \\
F V C \\
V_{\max } \max _{50} \\
\operatorname{Vmax}_{25} \\
\operatorname{Vmax}_{50}\left(\mathrm{He} / \mathrm{O}_{2}\right) \\
\operatorname{Vmax}_{25}\left(\mathrm{He} / \mathrm{O}_{2}\right)\end{array}$ & $\begin{array}{l}2 \cdot 6 \\
1 \cdot 2 \\
6 \cdot 6 \\
7 \cdot 3 \\
3 \cdot 1 \\
3 \cdot 0\end{array}$ & $\begin{array}{r}2 \cdot 0 \\
1 \cdot 2 \\
3 \cdot 5 \\
1 \cdot 5 \\
-1 \cdot 2 \\
-2 \cdot 8\end{array}$ & $\begin{array}{l}1 \cdot 2 \\
0 \cdot 2 \\
1 \cdot 2 \\
2 \cdot 8 \\
3 \cdot 5 \\
4 \cdot 0\end{array}$ & $\begin{array}{l}1 \cdot 0 \\
0 \\
2 \cdot 7 \\
3 \cdot 4 \\
-2 \cdot 0 \\
4 \cdot 1\end{array}$ & $\begin{array}{l}1 \cdot 8 \\
0 \cdot 8 \\
3 \cdot 8 \\
5 \cdot 1 \\
3 \cdot 3 \\
3 \cdot 5\end{array}$ & $\begin{array}{r}1 \cdot 5 \\
0 \cdot 6 \\
3 \cdot 1 \\
2 \cdot 5 \\
-1 \cdot 6 \\
0 \cdot 7\end{array}$ \\
\hline
\end{tabular}

No difference between smokers and non-smokers was statistically significant for any test. 


\section{References}

${ }^{1}$ Lapp NL, Hankinson JL, Burgess DB, O'Brien R. Changes in ventilatory function in coal miners after a work shift. Arch Environ Health 1972;24:204-8.

${ }^{2}$ Hutcheon M, Griffin P, Levison H, Zamel N. Volume of isoflow: a new test in detection of mild abnormalities of lung mechanics. Am Rev Respir Dis 1974;110:458-65.

${ }^{3}$ Guberan E, Williams MK, Walford J, Smith MM. Circadian variation of FEV in shift workers. Br J Ind Med 1969;26:121-5.

${ }^{4}$ McKerrow CB, McDermott M, Gilson JC, Schilling RSF. Respiratory function during the day in cotton workers. $\mathrm{Br} J$ Ind Med 1958;15:75-83.
${ }^{5}$ Lewinsohn H, Capel L, Smart J. Changes in forced expiratory volumes throughout the day. $\mathrm{Br} \mathrm{Med} \mathrm{J} \mathrm{1960;i:462-4.}$

${ }^{6}$ Winget CM, Hughes L, Ladou J. Physiological effects of rotational work shifting. A review. JOM 1978;20:204-10.

${ }^{7}$ Lortie M, Foret J, Teiger C, Laville A. Circadian rhythms and behaviour of permanent nightworkers. Int Arch Occup Environ Health 1979:44:1-11.

${ }^{8}$ Hankinson JL, Boehlecke B. Variability of spirometric pulmonary function studies. Am Rev Respir Dis 1981;123,suppl:148.

${ }^{9}$ Love RG, Attfield MD, Isles KD. Reproducibility of pulmonary function tests under laboratory and field conditions. $\mathrm{Br} J$ Ind Med 1980;37:63-9. 